OPEN ACCESS

Edited by:

Evan Preisser

University of Rhode Island,

United States

Reviewed by:

Meredith Sylvia Palmer,

University of Minnesota Twin Cities,

United States

Shawn M. Wilder,

Oklahoma State University,

United States

*Correspondence:

Fredrik Dalerum

dalerumjohan@uniovi.es

Specialty section:

This article was submitted to

Behavioral and Evolutionary Ecology,

a section of the journal

Frontiers in Ecology and Evolution

Received: 13 September 2018

Accepted: 02 November 2018

Published: 27 November 2018

Citation:

Chizzola M, Belton L, Ganswindt A,

Greco I, Hall G, Swanepoel $L$ and Dalerum F (2018) Landscape Level

Effects of Lion Presence (Panthera leo) on Two Contrasting Prey Species.

Front. Ecol. Evol. 6:191.

doi: 10.3389/fevo.2018.00191

\section{Landscape Level Effects of Lion Presence (Panthera leo) on Two Contrasting Prey Species}

\author{
Maddalena Chizzola ${ }^{1}$, Lydia Belton ${ }^{2}$, Andre Ganswindt ${ }^{2}$, Ilaria Greco ${ }^{1}$, Grant Hall ${ }^{2}$, \\ Lourens Swanepoel ${ }^{3}$ and Fredrik Dalerum 1,2,4*
}

${ }^{1}$ Department of Zoology, Stockholm University, Stockholm, Sweden, ${ }^{2}$ Mammal Research Institute, Department of Zoology and Entomology, University of Pretoria, Pretoria, South Africa, ${ }^{3}$ Department of Zoology, University of Venda, Thohoyandou, South Africa, ${ }^{4}$ Research Unit of Biodiversity (UMIB, UO-PA-CSIC), University of Oviedo, Mieres, Spain

Due to the strong individual cost of being predated, potential prey species alter their behavior and physiology in response to predation risk. Such alterations may cause major indirect consequences on prey populations that are additive to the direct demographic effects caused by prey being killed. However, although earlier studies showed strong general effects of the presence of apex predators, recent data suggest that indirect effects may be highly context dependent and not consistently present. We combined behavioral data with data on endocrine stress and stable isotopes to assess landscape level effects of lion (Panthera leo) presence on two prey species in South Africa, impala (Aepyceros melampus) and blue wildebeest (Connochaetes taurinus). We also evaluated if there was any seasonal variation in such effects. In addition, we provide results from a physiological validation for an enzyme-linked immunoassay (EIA) that can be used for non-invasive monitoring of glucocorticoid stress metabolite concentrations in impala from fecal pellets. We did not find any significant differences in vigilance behavior, fecal glucocorticoid metabolite concentrations, $\delta^{13} \mathrm{C}$ values or isotope niche breadth between animals living with and without lions for either species. However, wildebeest living in a reserve with lions spent more time foraging compared to wildebeest in a lion-free environment, but only during the wet season. Values of fecal $\delta^{15} \mathrm{~N}$ suggest a shift in habitat use, with impala and wildebeest living with lions potentially feeding in less productive areas compared to animals living without lions. For both species, characteristics of the social groups appeared to be more important than individual characteristics for both foraging and vigilance behavior. Our results highlight that antipredator responses may be highly dynamic and scale-dependent. We urge for further studies that quantify at what temporal and spatial scales predation risk is causing indirect effects on prey populations.

Keywords: anti-predator response, predation, lion, Africa, behavioral observation, stable isotopes, fecal glucocorticoid metabolites, validation 


\section{INTRODUCTION}

Predation has major impacts on ecosystem processes by influencing the dynamics of prey populations (Lima, 1998). The effects of predation on prey demography are partly caused by prey being killed, and partly by indirect effects caused by antipredatory responses (Lima, 1998; Creel and Christianson, 2008). These so called "risk effects" can be responsible for considerable portion of the total role of predation on prey demography (Creel and Christianson, 2008; Valeix et al., 2009; Creel et al., 2014). Behavioral responses to predation risk are diverse, but may include shifts in habitat use (Creel et al., 2005), changes in movement patterns (Sih and McCarthy, 2002), adjustment of the relative time spent vigilant and foraging (Lima and Bednekoff, 1999; Abramsky et al., 2002), and social aggregation (Lima, 1995). It can also trigger physiological stress responses (Clinchy et al., 2004), which may have negative effects on prey populations (Hawlena and Schmitz, 2010; Boonstra, 2013).

A number of studies from a wide range of taxa show that antipredator responses often lead to a decreased foraging success, caused by a shift in the trade-off between vigilance and feeding habits (Werner et al., 1983; Creel et al., 2014). Lima and Bednekoff (1999) suggested that under temporal fluctuations of predation risk, prey should balance their antipredator behavior and energetic intake requirements ("the risk allocation hypothesis"). Animals will spend more effort in antipredator behaviors when predation risk is high and prioritize feeding efficiency when predation risk is low and prolonged. In this situation, prey need to reduce anti-predator behavior in favor of food intake (Lima and Bednekoff, 1999). This tradeoff should become more pronounced in the presence of food limitation (Dias et al., 2011). In general, prey demography is affected by the reduction of foraging success to favor antipredator vigilance (Lima and Dill, 1990). Animals can also alter the amount of time spent vigilant or the frequency of scanning bouts, influencing their foraging behavior differentially (Roberts, 1996). The tendency of prey to forage gregariously promotes risk dilution and confusion effects, but also enhances the possibility to detect predation risk reducing an individual's time spent vigilant while favoring food intake (Elgar, 1989; Dalerum et al., 2008a). Several studies have demonstrated the cost of vigilance for foraging. For example, Wolff and Van Horn (2003) found that female elk (Cervus elaphus) in Yellowstone National Park, a predator-rich environment, spent more time being vigilant and less time foraging than female elk in Rocky Mountain National Park, a predator-free system.

Predation risk can also cause physiological stress responses, which include an increased activity of the hypothalamicpituitary-adrenal (HPA) axis (Hawlena and Schmitz, 2010). Increased levels of adrenocorticotrophic hormone (ACTH) promote the adrenal cortex to release glucocorticoids (GCs, i.e., cortisol or corticosterone), which induce elevation of blood pressure, cardiovascular function and respiration (Sapolsky et al., 2000). Elevated GC levels also directly inhibit the immune and digestive systems, and suppress growth and reproduction (Dobson and Smith, 2000). Therefore, a prolonged stress response may cause pathologies, such as inhibition of fundamental non-emergency body functions and drops in reproductive output, which may have far-reaching consequences for predator-prey dynamics (Boonstra et al., 1998; Creel et al., 2009; Hawlena and Schmitz, 2010). However, although most vertebrates show a physiological stress response to immediate predation risk, the occurrence of chronic stress as a response to anticipated predation may differ between prey species depending on life history characteristics (Boonstra, 2013).

Predation may also cause shifts in foraging patterns and habitat utilization, if animals are forced to feed in lower quality habitats to limit risk (Creel and Christianson, 2008). Prey tend can avoid areas with high predation risk by selecting habitats with better opportunities for detection of predators and better opportunities to escape (Valeix et al., 2009). However, the decisions associated with habitat use may involve trade-offs between nutritional needs to optimizing energy intake while simultaneously reducing the risk of predator exposure. For instance, a study in the Yellowstone National Park showed that the presence of wolf (Canis lupus) led elk to shift their habitat use from favored grassland to wooded areas, and to shift their feeding habits from grazing to browsing (Creel et al., 2005; Creel and Christianson, 2009). Similarly, Thaker et al. (2011) found that in Africa, smaller ungulates, such as impala (Aepyceros melampus), warthog (Phacochoerus africanus) and kudu (Tragelaphus strepsiceros) avoided the areas used by predators living nearby. However, larger ungulates, such as blue wildebeest (Connochaetes taurinus, hereafter referred to as wildebeest), plains zebra (Equus quagga) and giraffe (Giraffa camelopardalis) avoided areas utilized by larger predators, such as lions and leopards. Due to of such trade-offs, seasonal variation in food availability and quality can influence habitat choice (Jarman, 1974; Périquet et al., 2012).

African ecosystems support some of the most diverse groups of large carnivores and associated assemblages of ungulate prey on Earth (Sinclair et al., 2003; Dalerum et al., 2009; Dobson, 2009). Therefore, they offer excellent environments in which to evaluate the indirect effects of predation risk. The African savanna hosts diverse herbivore assemblages with species of contrasting morphology, physiology and behavior due to high plant diversity and spatiotemporal heterogeneity (du Toit et al., 2004). In the case of large herbivores, local extinction of predator populations may not necessarily cause a loss in the ability of prey species to respond to predators (Hettena et al., 2014), and ecologically naive prey in Africa have showed similar responses to lion exposure as populations facing lion predation (Dalerum and Belton, 2015). This finding agrees with evolutionary arguments for retention of anti-predatory behavior in multi-predatory environments (Blumstein, 2006), although it stands in contrast to some studies from the northern hemisphere (Sand et al., 2006; Berger, 2007). Hence, the repatriation of locally extinct African predators has the potential to rapidly reconstruct ecological effects of predation that may have been lost (Dalerum and Belton, 2015).

Stable carbon and nitrogen isotope measurements can be good indicators of the foraging ecology and habitat utilization of African ungulates (Codron et al., 2007; Miranda et al., 2014). Three main foraging strategies can be identified among African herbivores; grazers, browsers and mixed-feeders (Hofmann and Stewart, 1972). The majority of African grasses follow the C4 
photosynthetic pathway, whereas forbs, shrubs and trees utilize the C3 photosynthetic pathway. Because these pathways cause different rates of incorporation of ${ }^{13} \mathrm{C}$, stable carbon isotope ratios can be used to distinguish grasses from trees, shrubs and forbs (Farquhar et al., 1989). Subsequently, ${ }^{13} \mathrm{C} /{ }^{12} \mathrm{C}$ isotope ratios allow for the identification of feeding strategies in African ungulates (Codron J. et al., 2005). In contrast, ${ }^{15} \mathrm{~N} /{ }^{14} \mathrm{~N}$ ratios in plants reflect plant physiology and environmental conditions, such as aridity, soil type, climate and nitrogen sources (Handley and Raven, 1992). Stable nitrogen isotope ratios can be good indicators of habitat utilization (Ambrose and De Niro, 1986), although they may also reflect physiological mechanisms of rumination (Ambrose, 1991). Combining carbon and nitrogen isotope data may therefore offer complementary information regarding the ecology of African ungulates (Miranda et al., 2014).

In this study, we evaluated how the presence of lions (Panthera leo) influenced foraging and vigilance behavior, stress hormone levels, and stable isotope markers of foraging ecology in two African ungulates, impala and wildebeest. We compared data from two reserves in northern South Africa, of which one supports a re-introduced lion population, while the other has been without lions since they went regionally extinct over 100 years ago (Dalerum and Belton, 2015). We also provide a physiological validation for an enzyme-linked immunoassays (EIAs) to ensure its suitability for a non-invasive monitoring of a physiological stress response in impala measuring fecal glucocorticoid metabolite (fGCM) concentrations (Ganswindt et al., 2012). Wildebeest are one of the most preferred prey species for lions (Hayward and Kerley, 2005), whereas impala are one of the least preferred (Owen-Smith, 2008). Both species are gregarious ungulates (Périquet et al., 2012; Sagamiko et al., 2015), impala are mixed feeders utilizing both grassland and bushland habitats according to seasonal change in food resources (Miranda et al., 2014), whilst wildebeest are regarded as grazers usually confined to grassland areas (Codron et al., 2007; Valeix et al., 2009; Périquet et al., 2012).

We hypothesized that the presence of lions would affect behavioral time budgets, stress-related hormone concentrations and foraging ecology of both species, and made the following predictions: (1) ungulates living in the presence of lions will forage less and be more vigilant than ungulates living in a lionfree environment; (2) ungulates living in an area with lions will have higher stress hormone concentrations than ungulates living in a lion-free environment; (3) lions will influence the foraging patterns in the two ungulates which will be reflected in the stable isotope ratios; (4) the effects of lions on time budgets will be most pronounced during the dry season, which has limited resources; and (5) the presence of lions will have an overall greater effect on the behavior of the most preferred prey, wildebeest, than on impala.

\section{METHODS}

\section{Study Area}

We conducted the study in two reserves in the Waterberg region of the Limpopo province, South Africa (Figure 1A). The Waterberg region was declared a biosphere reserve (the
Waterberg Biosphere Reserve) by United Nations Educational, Scientific and Cultural Organization (UNESCO) in 2001 (PoolStanvliet, 2013). The region is dominated by highland plateaus and steep rocky hills and the altitude ranges from $1,100 \mathrm{~m}$ in the north-west to $2,100 \mathrm{~m}$ in the south-western part of the area (Wellington, 1955; Dalerum and Belton, 2015). The area is characterized by numerous small and large rivers, streams and gullies, but other water support systems, such as wetlands, marshes and artificial waterholes are present (Swanepoel, 2008). The vegetation is classified as Waterberg Mountain Bushveld, where the flora ranges from short closed woodland to low brake (Mucina and Rutherford, 2006). The area is located in a summer rainfall region with distinct dry (April-September) and wet (October-March) seasons (Codron D. et al., 2005). The mean annual rainfall ranges from 650 to $900 \mathrm{~mm}$ with more intense precipitation during the wet season with a maximum monthly rainfall of $302.6 \mathrm{~mm}$ (Low and Rebelo, 1996). The mean annual maximum temperature is $26.5^{\circ} \mathrm{C}$ and the mean annual minimum temperature is $11^{\circ} \mathrm{C}$ (Kilian, 2003). The average maximum summer temperature is $32^{\circ} \mathrm{C}$ and the minimum is $18^{\circ} \mathrm{C}$. In winter, the mean maximum temperature is $22^{\circ} \mathrm{C}$ and the mean minimum is $4^{\circ} \mathrm{C}$, with the possibility of frost to occur (Ben-Shahar, 1987).

The study was conducted in two private reserves, Lapalala Wilderness (hereafter Lapalala, 2351S, 28 ${ }^{\circ} 16 \mathrm{E}$ ) and Welgevonden Game Reserve (hereafter Welgevonden, $\left.24^{\circ} 18 \mathrm{~S}, 27^{\circ} 80 \mathrm{E}\right)$. Both study areas were previously agricultural lands which were transformed into wilderness areas in 1993 and 1981, respectively. The two reserves are $50 \mathrm{~km}$ apart and similar in size, topography, geology, hydrology, vegetation and fauna (Figure 1B, Dalerum and Belton, 2015). In both reserves, upland areas are based on quartzite soils and low productivity semi-open woodlands, whereas lower elevations are characterized by a mixture of sand and clay based soils of higher productivity, with more open grassland patches. These areas of contrasting productivity are approximately equally distributed in the two areas. Both properties are privately owned and heavily fenced. Lapalala covers about $36,000 \mathrm{~h}$ and was at the time of data collection closed to the public. However, Lapalala hosted a wilderness school and a limited number of guided trophy hunts were permitted (Dalerum and Belton, 2015). Welgevonden, which encompasses 37,500 ha, contains 15 commercial game lodges and several private ones. Over 50 land-owners have access rights over Welgevonden. Hunting is prohibited, but game-viewing is allowed (Dalerum and Belton, 2015). Our observations suggest that most animals have become habituated to game viewing vehicles, as has been suggested elsewhere (Bateman and Fleming, 2017). In both reserves, managementrelated activities, such as burning and bush-clearing occurred during the study (Isaacs et al., 2013).

Both study areas support abundant and diverse populations of herbivores, from large-sized ungulates, such as giraffe, white (Ceratotherium simum) and black (Diceros bicornis) rhinos, plains zebra, blue wildebeest and greater kudu to medium-sized ungulates like impala and warthog (Isaacs et al., 2013; Dalerum and Belton, 2015). Similarly, both reserves have similar resident carnivore communities including brown hyena (Parahyaena 
A

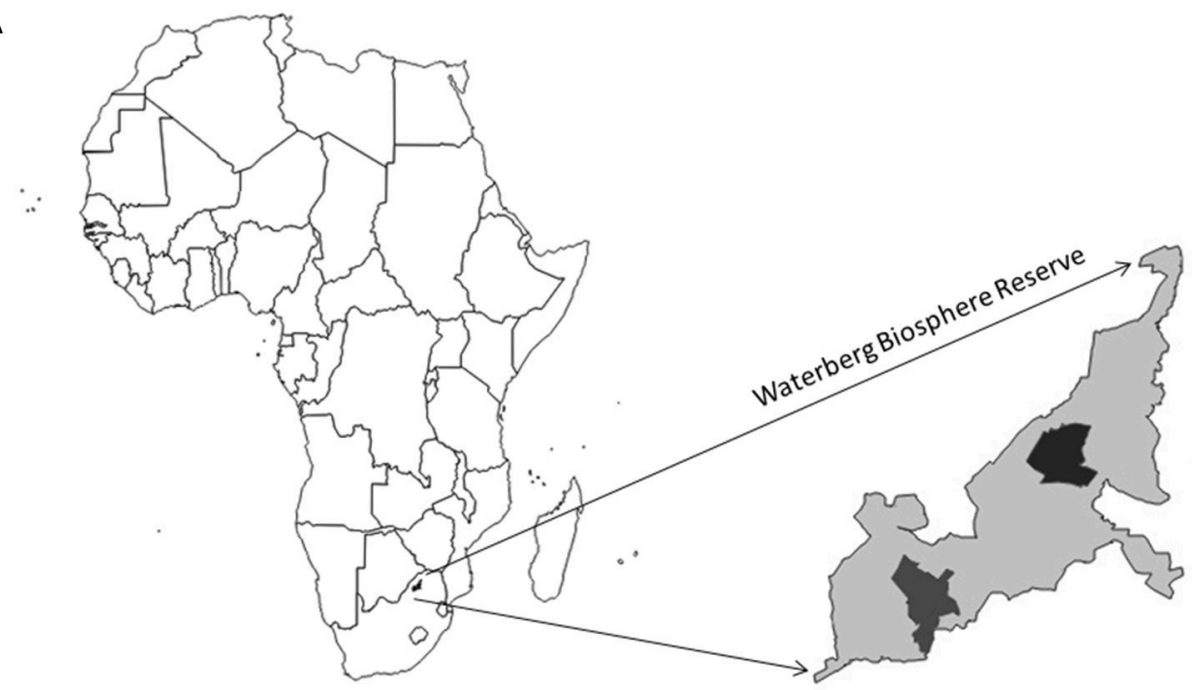

B

Welgevonden

Lapalala

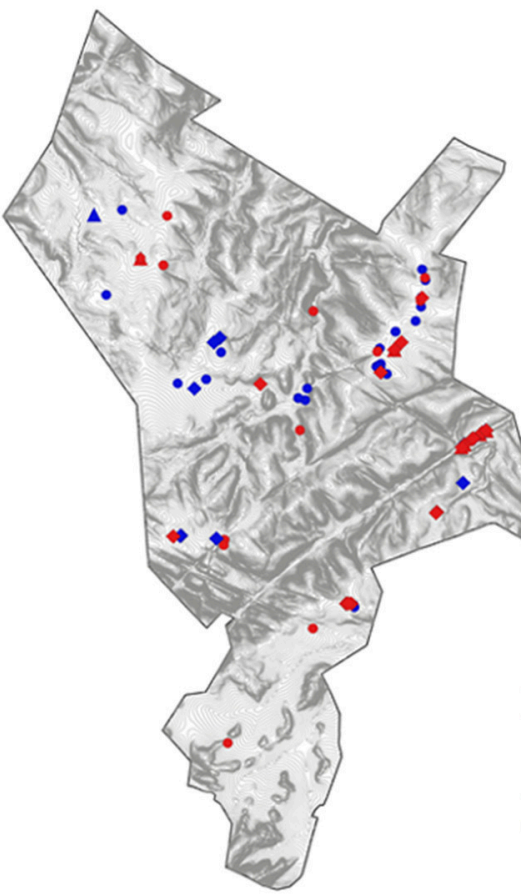

A Impala faecal sample: isotope analysis

\ Wildebeest facel sample: isotope analysis

- Impala faecal sample: isotope and hormone analysis

- Wildebeest faecal sample: isotope and hormone analysis

- Location of behavioral observation of impala

- Location of behavioral observation of wildebeest

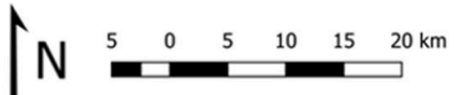

FIGURE 1 | Location of the two study sites within the Waterberg Biosphere Reserve (A) as well as detailed maps of each reserve including locations for behavioral observations and collected fecal samples (B).

brunnea), black-backed jackal (Canis mesomelas) and leopard (Panther pardus) (Swanepoel et al., 2015). Individual cheetahs (Acinonyx jubatus) are transitory in Lapalala and occasionally present in Welgevonden (Dalerum and Belton, 2015), while wild dog (Lycaon pictus) occasionally occur in Lapalala (Ramnanan et al., 2013). Lapalala is characterized by the absence of lions, which were eradicated in the north-central part of South-Africa at the beginning of the twentieth century (Skead, 2011). Conversely, to develop Welgevonden as a Big Five wildlife reserve, lions were reintroduced in 1998 together with elephant (Loxodonta ajricana), white rhinocero and buffalo (Syncerus caffer) (Kilian, 2003). Apart from these differences, densities of ungulates and 
carnivores were comparable between the reserves, although temporal fluctuations occurred (Dalerum and Belton, 2015; Swanepoel et al., 2015). At the time of data collection (20082012), Welgevonden hosted a lion population ranging from 8 to 14 animals, distributed across two prides and one male coalition (Dalerum and Belton, 2015). The two reserves are separated by $\sim 50 \mathrm{~km}$ of farmland, so there is very little likelihood of the Welgevonden lions moving into the Lapalala area and it is unlikely that prey species have dispersed between them (Dalerum and Belton, 2015).

\section{Collection of Behavioral Data}

Behavioral observation periods of 1-2 weeks took place from July 2008 to June 2012, during both the dry and wet seasons. We opportunistically encountered groups of herbivores while driving in the reserve at dawn and dusk, and recorded data from groups where at least half of the animals were actively foraging to avoid biases associated with animals experiencing different motivational drivers for various behaviors (Dalerum et al., 2008a, see also Clutton-Brock et al., 1999). The observations were conducted in open landscape or open patches in the woodlands throughout both reserves (Figure 1B). Observations of the same group were prevented as far as possible by avoiding repeated sampling at the same location during each field period. Although this may have prevented pseudo replication within each season, we cannot rule out that the same groups were observed during different years and seasons. Groups were observed from within a vehicle at distances ranging from 25 to $200 \mathrm{~m}$ from the animals. For each group, the group size and the group composition based on a crude age class distinction (adult, sub-adult and juvenile) and sex was noted, as well as distance of the center of the group to nearest available cover. These distances ranged from 0 to 300 meters for both impala and wildebeest. While distance to cover did not differ between the reserves for impala (Lapalala [mean $\pm \mathrm{sd}$ ]: $54 \pm 76 \mathrm{~m}$, Welgevonden: $44 \pm 46 \mathrm{~m}, \beta=-11.4$, $\left.t_{56}=0.60, p=0.553\right)$, wildebeest had longer distance to cover in Welgevonden $(110 \pm 88 \mathrm{~m})$ than in Lapalala $(48 \pm 50 \mathrm{~m})$ $\left(\beta=66.8, t_{41}=2.80, p=0.008\right)$. We recorded the whole group, or as large part of the group as possible, for $5 \mathrm{~min}$ or until the group was out of view using a small handheld digital video camera. Recordings were not initiated until the group showed no signs of disturbance from the observation vehicle (Dalerum and Belton, 2015). We also conducted scan observations of the groups while they were being observed in the field.

Time spent foraging and being vigilant was quantified using focal sampling techniques from the recorded videos (Altmann, 1974; Dalerum and Belton, 2015). The duration of all behaviors was timed to the closest second by recording them on a PDA device or onto a laptop computer (Dalerum and Belton, 2015). We also counted the number of vigilance scan bouts for each focal individual. The focal observations on each adult or sub-adult group member was done for $5 \mathrm{~min}$ or until the individual was out of sight. Animals with $<90 \mathrm{~s}$ of observation were excluded from analyses. An animal was defined as foraging if it was standing up with its head distinctly below its shoulders or if it was standing up and feeding from a bush. Animals were defined as vigilant if they were standing up with their head clearly above their shoulders and scanning the surroundings. We attempted to distinguish social from anti-predatory vigilance, and discarded all vigilance bouts where vigilance clearly was directed towards group members.

The scan observations were conducted by simultaneously recording the activity of each individual at specific time points and summarizing the number of animals engaged in each behavior. Animals for which we could not define the behavior because they were obscured or out of sight were omitted from that individual scan. In contrast to the focal observations, which give behavioral time budgets, the scan observations provide an indication of how large a proportion of each group are engaged in the respective behaviors at a given time. Scan observations were scored at 1 -min intervals for $5 \mathrm{~min}$. For each scan event, we calculated the proportions of the total number of observable adult and sub-adult individuals that were engaged in foraging and vigilance for subsequent analyses (Dalerum and Belton, 2015).

Throughout the two seasons we scored behavior from a total of 171 impala (95 in dry and 76 in wet) and 106 wildebeest individuals (64 in dry and 42 in wet) belonging respectively to 42 and 29 groups in Lapalala for focal recordings, and 75 impala (29 in dry and 46 in wet) and 61 wildebeest (46 in dry and 15 in wet season), respectively distributed in 16 and 14 groups in Welgevonden. Number of individuals per group ranged from 1 to 7 for impala and from 1 to 5 for wildebeest. For scan observations we recorded a total of 33 groups of impala (21 in dry and 12 in wet season) and 22 groups of wildebeest (13 in dry and 9 in wet season) in Lapalala, and 15 groups of impala (6 in dry and 9 in wet season) and 11 groups of wildebeest ( 8 in dry and 3 in wet season) in Welgevonden.

\section{Collection of Fecal Samples and Plant Reference Samples}

Fecal samples from the target species were collected from the two reserves during the same periods as the behavioral recordings, i.e., from July 2008 to June 2012. Fecal samples were used for both glucocorticoid metabolite and isotope analyses. Groups or single study animals were spotted from a vehicle and followed until they defecated. Feces were collected within $15 \mathrm{~min}$ after defecation, put into labeled zip-lock bags, and stored in a cooling box containing ice to avoid bacterial and microbial degradation of fGCMs (Hulsman et al., 2011). Back at the research base, the samples were stored in a freezer at $-20^{\circ} \mathrm{C}$. Samples were collected only from adult or sub-adult individuals and we noted age, sex as well as group size and composition. Attempts were made to collect a unique sample per group in order to decrease interdependency between samples (Miranda et al., 2014). A total of 85 impala samples were collected for $\mathrm{C}$ and $\mathrm{N}$ isotope analysis, from 59 individuals (24 in dry and 35 in wet season) that belonged to 46 groups in Lapalala and 26 individuals ( 5 in dry and 21 in wet season) that belonged to 17 groups in Welgevonden. A total of 56 wildebeest samples were collected, of which 29 individuals (14 in dry and 15 in wet season) belonged to 24 groups in Lapalala, and 27 animals (9 in dry and 18 in wet season) belonged to 23 groups in Welgevonden. 
In order to provide a baseline isotopic dataset for interpreting the stable isotope values from the fecal samples, 34 reference plant samples from 10 different species in Lapalala were collected. These were either shrubs or grasses and were collected in diverse topographical sites to reflect a wide range of environmental conditions. These reference samples were collected during the dry season in 2017.

\section{Hormone Analysis}

The evaluation of physiological stress was determined noninvasively by measuring fGCM concentrations using a random sub-set of the collected fecal samples. The analysis were performed on 43 fecal samples of impala (18 in dry and 25 in wet season) from 31 groups in Lapalala and on 19 impala samples (7 in dry and 12 in wet) from 14 groups in Welgevonden. We analyzed $27 \mathrm{fecal}$ samples of wildebeest (10 in dry and 17 in wet season) from 22 groups in Lapalala, and 27 samples ( 9 in dry and 18 in wet season) from 23 groups in Welgevonden for a total of 54 samples for this species.

We lyophilized the fecal samples for $72 \mathrm{~h}$ and pulverized them using a pestle and mortar in order to remove solid inert matter, such as seeds and fibrous dietary material (Heistermann et al., 1993). A sample of about $0.010-0.011 \mathrm{~g}$ of dry powder was extracted by vortexing for $15 \mathrm{~min}$ with $80 \%$ ethanol in water $(3 \mathrm{ml})$. Afterwards, the suspension was centrifuged at $1,500 \mathrm{~g}$ for $10 \mathrm{~min}$ and the supernatant decanted into Eppendorf tubes, which were stored at $-20^{\circ} \mathrm{C}$ until hormone analysis. Immunoreactive fecal glucocorticoid metabolite (fGCM) concentrations were measured from the fecal extracts of Impala and Wildebeest samples using enzyme immunoassays (EIAs). For impala we used an antibody detecting fGCMs with a $5 \beta$-3 $\alpha$-ol-11-one structure $(3 \alpha, 11$ oxoCM) previously described by Möstl and Palme (2002), and for wildebeest an antibody detecting 11,17 dioxoandrostanes (11,17-DOA) previously described by Palme and Möstl (1997). The sensitivity of the 11,17-DOA and $3 \alpha, 11$ oxo-CM EIAs was $0.6 \mathrm{ng} / \mathrm{g}$ dry weight, respectively. Intra-assay coefficient of variation of high- and low-value quality controls were 3.05 and $5.71 \%$ for the 11,17 -DOA EIA, and 5.27 and $5.76 \%$ for the $3 \alpha, 11$ oxo-CM EIA, respectively. Inter-assay coefficient of variation of high- and low-value quality controls were 3.84 and $6.59 \%$ for the 11,17 -DOA EIA, and 10.39 and $12.15 \%$ for the $3 \alpha, 11$ oxo-CM EIA. These antibodies were selected because they provided the strongest species-specific response in fGCM concentrations during physiological validation using ACTH challenge tests. Respective validation experiments have been described elsewhere for wildebeest (de Haast, 2016), whereas the ACTH challenge test for impala is described below. We expressed fGCM concentrations as $\mu \mathrm{g} / \mathrm{g}$ dry of weight extracted fecal material. All fecal samples were analyzed at the Endocrine Research Laboratory, University of Pretoria, South Africa.

\section{ACTH Challenge Test for Impala}

We physiologically validated an assay for the measurement of fGCMs in impala by conducting an adrenocorticotrophic hormone (ACTH) challenge test (Touma and Palme, 2005). The tests were done on three adult impala males located in standard hospital enclosures at the National Zoological Gardens (NZG) of South Africa, Pretoria. They were housed singly but adjacent to conspecifics. The animals were injected with $0.5-1.0 \mathrm{IU} / \mathrm{kg}$ of Synacthen depot (Novartis, Australia) intramuscularly via remote injection (Daninject 1.5 or $3 \mathrm{ml} \mathrm{dart).} \mathrm{A} 20 \times 1.5 \mathrm{~mm}$ barbless needle was attached to the darts, which fell out within 1$2 \mathrm{~h}$. Fecal samples were collected daily from each individual for 57 days prior to ACTH administration and $72 \mathrm{~h}$ post-injection and 1-2 samples per day during the following 3-4 days. We collected respective sample material from the center of a dropping to avoid cross-contamination with urine or contamination with other nearby scats. A portion of 5-10 g was homogenized and stored in individual collection vials and frozen immediately upon collection at $-20^{\circ} \mathrm{C}$. We used the same extraction protocol as described above (2.4). Using partly a reduced sample set, we evaluated EIAs detecting (i) 11,17-dioxoandrostane (11,17DOA), (ii) fGCMs with a $5 \beta$-3 $\alpha$-ol-11-one structure $(3 \alpha, 11$ oxo$\mathrm{CM}$ ), as well as (iii) a cortisol and ivcorticosterone EIA. For more details on these EIAs, see Palme and Möstl (1997) for the corticosterone, cortisol, and 11,17-DOA assays, and Möstl and Palme (2002) for the $3 \alpha, 11$ oxo-CM assay. Following the experiment, the animals were given access to join each other for the acclimatization period before being loaded and returned to their standard enclosures.

Of the four different assays tested, the $3 \alpha, 11$ oxo-CM assay detected the strongest response and was regarded as the most appropriate assay for impala. This assay showed post-injection peak concentrations of 232\% (animal 1), 936\% (animal 2), and 936\% (animal 3) above baseline (Figure S1A). In terms of performance, this assay was followed by the 11,17-DOA EIA (animal 1: 142\%; animal 2: 597\%; animal 3: 338\%; Figure S1B). Peak values for both of these assays occurred about $20 \mathrm{~h}$ postinjection. The corticosterone EIA showed a less pronounced increase (animal 1: 104\%; animal 2: 138\%; animal 3: 214\%) with no consistent peak in time (Figure S1C), whereas the cortisol EIA showed inconsistent results with no increase post-injection detected in samples from animal 1 (96\%) and only low increases in the other two individuals (animal 2: 163\%; animal 3: 119\%, Figure S1D).

\section{Isotope Analyses}

For the isotope analyses, fecal material was oven dried at $37^{\circ} \mathrm{C}$ for at least $24 \mathrm{~h}$, all traces of surface contaminants removed and then pulverized with a mortar and pestle (Miranda et al., 2014). All equipment was cleaned with $70 \%$ ethanol between samples. Aliquots of $1.0-1.1 \mathrm{mg}$ of fecal powder were weighed into tin capsules that had been pre-cleaned with toluene. Isotope analysis was done on a Flash EA 1112 Series coupled to a Delta V Plus stable light isotope ratio mass spectrometer via a ConFlo IV system (all equipment supplied by Thermo Fischer, Bremen, Germany). Fecal stable isotope analyses were conducted at the UP Stable Isotope Laboratory at the Mammal Research Institute, University of Pretoria, South Africa. Carbon isotope ratios are referenced to Vienna Pee-Dee Belemnite, whereas nitrogen isotope values reference to atmospheric $\mathrm{N}_{2}$. Results are expressed in delta notation with a per mill (\%o) scale using the 
standard equation:

$$
\delta X(\%)=\left[\left(\mathrm{R}_{\text {sample }} / \mathrm{R}_{\text {standard }}\right)-1\right] \times 1,000
$$

where $\mathrm{X}={ }^{13} \mathrm{C}$ or ${ }^{15} \mathrm{~N}$ and $\mathrm{R}$ represents ${ }^{13} \mathrm{C} /{ }^{12} \mathrm{C}$ or ${ }^{15} \mathrm{~N} /{ }^{14} \mathrm{~N}$, respectively.

Two laboratory running standards (Merck Gel: $\delta^{13} \mathrm{C}=-20.26 \%$ o, $\delta^{15} \mathrm{~N}=7.89 \%$, C $\left.\%=41.28, \mathrm{~N} \%=15.29\right) \&$ (DL-Valine: $\delta^{13} \mathrm{C}=-10.57 \%$, $\delta^{15} \mathrm{~N}=-6.15 \%$, C $\%=55.50$, $\mathrm{N} \%=11.86)$ and a blank sample were run after every 11 unknown samples. Data corrections were performed using results for the Merck Gel standard for each run. The results for the DL-Valine standard provided the precision for each run, which was $<0.08 \%$ for both carbon and nitrogen, respectively.

\section{Data Analysis}

For all analyses described below, separate models were run for each species. These models included the presence or absence of lions (i.e., reserve), season, their interaction effect as well as the main effects of group size, the number of juveniles, age and sex as fixed terms, except for models on scan data where we did not fit effects of sex and age. They also included group identity and year as random terms. We used generalized linear mixed-effects models with a binomial error and a logit link to evaluate the effect of the presence of lions and season on the proportion of time animals were engaged in foraging and vigilance as well as on the proportion of animals engaged in foraging and vigilance. For the models on the focal data, we regarded each second as a binomial variable that could be spent doing the behavior in question (i.e., foraging or being vigilant) or not (Dalerum and Belton, 2015; Périquet et al., 2017). We therefore added the number of seconds an animal spent foraging and vigilant in relation to the number of second the animals were not foraging and vigilant as response variables for each individual, and the number of foraging and vigilant animals in relation to the total number of observed animals estimated from the scan data as response variables for each group. We used generalized linear mixed-effects models with a Poisson error and a $\log$ link to evaluate the effect of the presence of lions and season on the number of vigilance bouts. These models had the number of vigilance bouts recorded for each focal observation as response observation length as an offset to correct for unequal length of the different observation periods. For all models on behavior, we initially used distance to cover as an additional fixed co-variate. However, since this did not approach significance for any model $(p>0.18$ for all models), we did not retain distance to cover in the final set of analyses. We used mixed linear models to evaluate the effects of presence of lions and season on fGCM concentrations. In these models, the fGCM concentrations were log-transformed to account for heteroscedasticity before being used as a response variable. Similarly, we evaluated the effects of presence of lions and season on isotope values and isotope niche breadth using mixed linear models. Raw values were used a response variable for the models on $\delta^{13} \mathrm{C}$, whereas $\log$ transformed values were used as response variables for the model on $\delta^{15} \mathrm{~N}$ for wildebeest and the model on estimates of isotope niche breadth (see below) for impala. Isotope niche breadth was quantified for each species and season as the mean Euclidian distance from each sample to the group centroid of each reserve and season in a twodimensional isotope space formed by $\delta^{13} \mathrm{C}$ and $\delta^{15} \mathrm{~N}$ values (Dalerum et al., 2012). For all analyses, we treated an alpha error of 0.05 as a threshold of statistical significance. Statistical analysis was conducted in R version 3.4.4 for Linux (http://www.r-project. org) using the nlme (Pinheiro et al., 2018) and MASS packages (Venables and Ripley, 2002).

\section{Animal Ethics and Institutional Approval}

The study was performed with approval of the Animal Use and Care Committee of University of Pretoria (AUCC, Reference EC17-12) the Ethics and Scientific Committee of the National Zoological Gardens of South Africa, Pretoria (Reference \# $\mathrm{PlO} / 33)$.

\section{RESULTS}

\section{Foraging Behavior}

Based on our focal observations, the presence of lions did not seem to influence the proportion of time that either impalas $\left(\beta=0.03, t_{49}=0.39, p=0.700\right)$ or wildebeests $(\beta=0.07$, $\left.t_{23}=0.67, p=0.508\right)$ spent foraging (Figure 2A), nor did effects of lions differ between seasons (impala: $\beta=0.09, t_{49}=0.79$, $p=0.436$; wildebeest: $\beta=0.21, t_{23}=1.07, p=0.256$ ). Similarly, there were no differences between the two seasons in the proportion of time spent foraging for either impala $(\beta=0.05$, $\left.t_{49}=0.91, p=0.367\right)$ or wildebeest $\left(\beta=0.03, t_{23}=28\right.$, $p=0.780$ ). Group size was positively associated to the amount of time spent foraging in impala, but not the number of juveniles, whereas neither group size nor sex influenced the proportion of time foraging in wildebeest (Table 1). Sub-adult animals spent less time foraging compared to adult individuals for both impala and wildebeest, but there were no effects of sex for either species (Table 1).

Based on our scan observations, the presence of lions did not seem to influence the proportion of impalas that were engaged in foraging $\left(\beta=0.00, t_{39}=0.05, p=0.962\right)$, nor did any such effects differ between seasons $\left(\beta=0.09, t_{39}=0.69, p=0.49\right.$ ). For wildebeest, however, there was a seasonal difference in the effects of lions ( $\beta=0.25, t_{24}=2.08, p=0.048$ ), with more animals being engaged in foraging in the presence of lions during the wet, but not the dry season (Figure 3A). Neither group size nor the number of juveniles influenced the proportion of animals engaged in foraging for either species (Table 1).

\section{Vigilance Behavior}

Based on our focal observations, the presence of lions did not seem to influence the proportion of time that impalas ( $\beta=0.29$, $\left.t_{49}=0.92, p=0.364\right)$ or wildebeests $\left(\beta=0.74, t_{23}=1.50\right.$, $p=0.146$ ) spent being vigilant (Figure 2B), nor were there any seasonal differences (impala: $\beta=0.04, t_{49}=0.10, p=0.921$; wildebeest: $\left.\beta=1.78, t_{23}=1.80, p=0.084\right)$. However, impala spent less time being vigilant in the wet than in the dry season ( $\left.\beta=0.46, t_{49}=2.18, p=0.034\right)$, but there were no seasonal differences for wildebeest $\left(\beta=0.32, t_{23}=0.72, p=0.476\right.$, Figure 2B). The proportion of time spent vigilant was negatively 


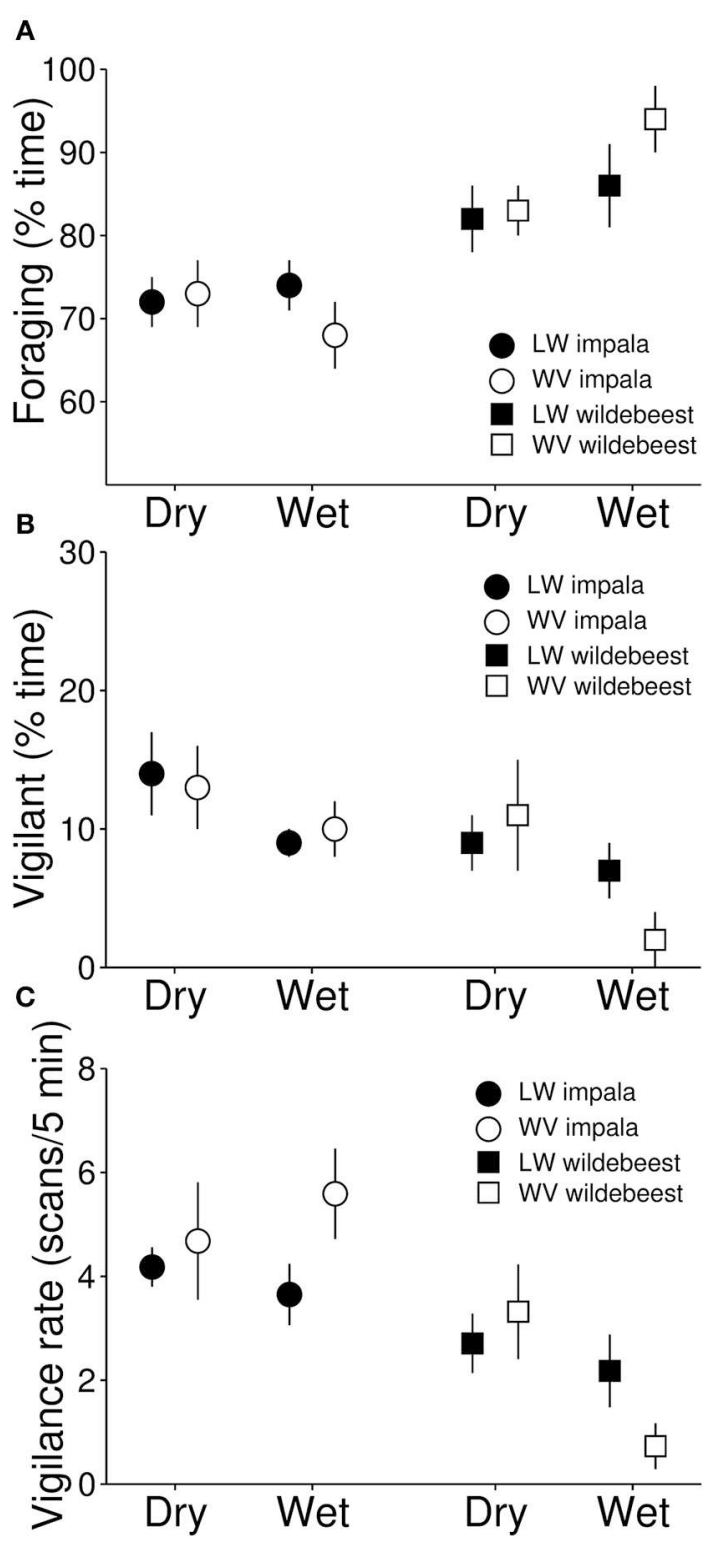

FIGURE 2 | Proportion of time spent foraging (A), proportion of time spent vigilant (B) and vigilance scan rates (scans $/ 5$ min observation period; C) calculated from a total of 413 individuals during $5 \mathrm{~min}$ focal observations conduced on 42 groups of impala and 29 groups of wildebeest in Lapalala and 16 groups of impala and 14 groups of wildedebeest in Welgevonden. The figure represents means of group means $\pm 1 \mathrm{SE}$.

associated to group size in impala, but not in wildebeest and there was no effect of the number of juveniles for either species (Table 1). Sub-adult impalas spent more time being vigilant than adults, while age did not affect the proportion of time being vigilant in wildebeest. Similarly, there were no effects of sex on the proportion of time spent vigilant for either species (Table 1).

Similarly based on the focal observations, the presence of lions did not seem to influence vigilance scan rate in either impala $\left(\beta=0.09, t_{49}=0.41, p=0.68\right)$ or in wildebeest $(\beta=0.58$, $t_{23}=1.48, p=0.152$ ), nor did season influence any such effects (impala: $\beta=0.43, t_{49}=1.56, p=0.125$; wildebeest: $\beta=1.44, t_{23}=1.76, p=0.092$, Figure $\left.2 \mathrm{C}\right)$. Similarly, there were no differences between seasons for either impala $(\beta=0.23$, $\left.t_{49}=1.49, p=0.144\right)$ or wildebeest $\left(\beta=0.04, t_{23}=1.12\right.$, $p=0.909)$. Group size was negatively associated while the number of juveniles was positively associated with vigilance scan rate in impala but not in wildebeest, whereas neither age nor sex was associated with vigilance scan rate of either species (Table 1).

Based on the scan observations, the presence of lions did not seem to influence the proportion of either impala $(\beta=0.25$, $\left.t_{39}=0.71, p=0.479\right)$ or wildebeest $\left(\beta=0.16, t_{24}=0.48\right.$, $p=0.632)$ that were vigilant, nor did seasons influence any such effects (impala: $\beta=0.16, t_{39}=0.35, p=0.782$; wildebeest: $\beta=27.96, t_{24}=0.00, p=0.999$, Figure 3B). Group size was negatively associated with proportion of animals being vigilant for impala but not for wildebeest, whereas the number of juveniles was negatively associated to the proportion of animals being vigilant for wildebeest but not for impala (Table 1).

\section{Stress Hormone Levels}

The presence of lions did not influence fGCM concentrations in samples from either impalas $\left(\beta=0.27, t_{35}=0.93, p=0.358\right.$, Figure 4A) or wildebeests $\left(\beta=0.14, t_{35}=0.46, p=0.650\right.$, Figure 4B), nor did season influence any such effects (impala: $\beta=0.20, t_{35}=0.58, p=0.563$; wildebeest: $\beta=0.16, t_{35}=0.42$, $p=0.679)$. Similarly, there were no differences between seasons for either impala $\left(\beta=0.26, t_{35}=1.03, p=0.310\right)$ or wildebeest $\left(\beta=0.31, t_{35}=1.14, p=0.262\right)$. Group size did not influence fGCM concentrations in either species, but the number of juveniles was positively associated with fGCM concentrations in impala but not in wildebeest (Table 2). Neither age nor sex influenced fGCM concentrations.

\section{Stable Isotope Values Reference Plant Values}

Grasses were enriched in ${ }^{13} \mathrm{C}$ compared to shrubs, which correspond to plants following a $\mathrm{C} 4$ pathway. Conversely, we observed lower $\delta^{13} \mathrm{C}$ values in shrubs, which is characteristic of a C3 photosynthesis pathway. Plant $\delta^{15} \mathrm{~N}$ values had lower inter specific variation than what was observed for $\delta^{13} \mathrm{C}$, but grass had slightly lower values compared to shrubs (Table S1).

\section{Carbon Isotope Values in Ungulate Feces}

The presence of lions did not influence $\delta^{13} \mathrm{C}$ values in feces from either species (impala: $\beta=1.24, t_{53}=1.15, p=0.255$; wildebeest: $\left.\beta=0.01, t_{35}=0.60, p=0.553\right)$, nor was there a seasonal variation of any such effects (impala: $\beta=0.83, t_{53}=0.66$, $p=0.51$; wildebeest: $\left.\beta=0.01, t_{35}=0.30, p=0.766\right)$. However, samples from both impala $\left(\beta=4.28, t_{53}=6.42, p<0.001\right)$ and wildebeest feces $\left(\beta=-0.06, t_{35}=3.29, p=0.002\right)$ were enriched in ${ }^{13} \mathrm{C}$ in the wet compared to the dry season. Values for impala reflected a mixed-strategy during the dry and a grazing feeding strategy during the wet season whereas wildebeest values for both seasons conformed to a strict grazing feeding strategy (Figure 5A). Neither group size, the number of juveniles nor sex influenced $\delta^{13} \mathrm{C}$ values, but sub-adult wildebeest had lower $\delta^{13} \mathrm{C}$ values than adults (Table 2 ). 


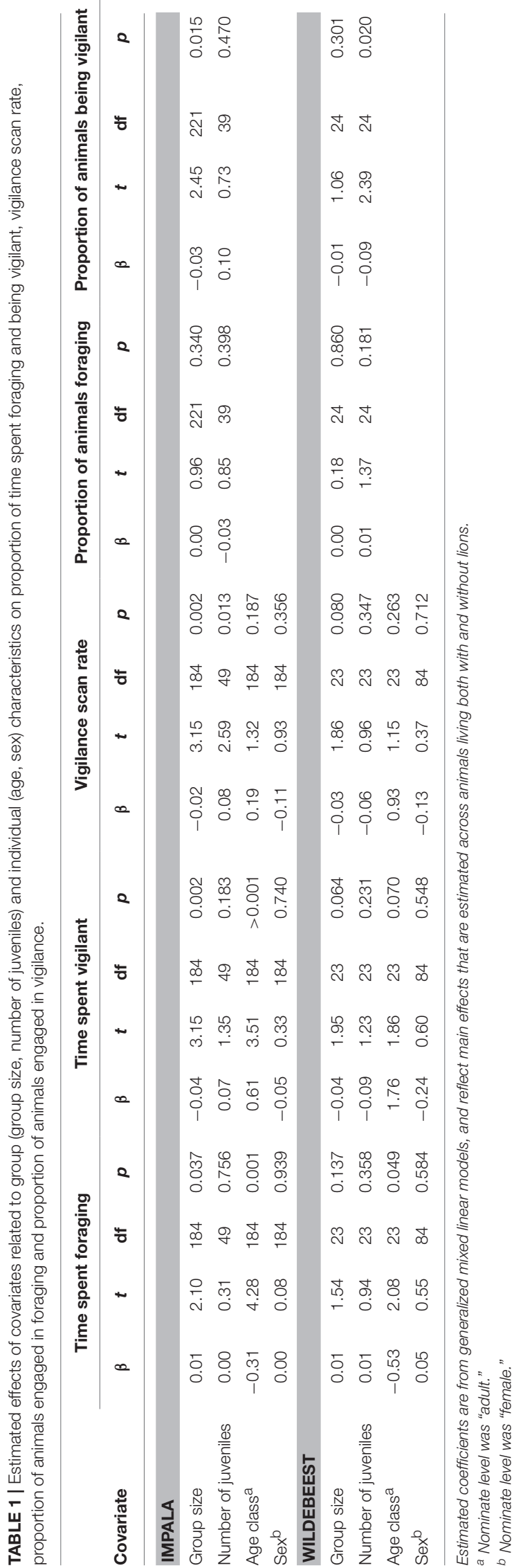

\section{Nitrogen Isotope Values in Ungulate Feces}

Feces from both impala $\left(\beta=1.32, t_{53}=2.18, p=0.034\right)$ and wildebeest $\left(\beta=0.94, t_{35}=3.86, p<0.001\right)$ that were living with lions had higher $\delta^{15} \mathrm{~N}$ values than feces from animals living in a lion free environment (Figure 5B). However, there were no seasonal differences in these effects for either species (impala: $\beta=0.64, t_{53}=0.90, p=0.370$; wildebeest: $\beta=0.22, t_{35}=0.46$, $p=0.651$ ), although feces from the wet season had higher $\delta^{15} \mathrm{~N}$ values than feces from the dry season for animals from both environments (impala: $\beta=0.88, t_{53}=2.32, p=0.024$; wildebeest: $\left.\beta=1.35, t_{35}=3.86, p<0.001\right)$. Neither group size, the number of juveniles, age nor sex influenced $\delta^{15} \mathrm{~N}$ values (Table 2).

\section{Isotope Niche Breadth Estimated From Isotope Values in Ungulate Feces}

The presence of lions did not influence isotope niche breadth for either species (impala: $\beta=0.36, t_{53}=1.22, p=0.23$; wildebeest: $\left.\beta=0.42, t_{35}=1.20, p=0.24\right)$, nor was there a seasonal variation of any such effects (impala: $\beta=0.48, t_{53}=1.39$, $p=0.169$; wildebeest: $\beta=0.33, t_{35}=0.73, p=0.469$, Figure 5C). Similarly, there were no differences between seasons in isotope niche breadth (impala: $\beta=0.00, t_{53}=0.01, p=0.989$; wildebeest: $\left.\beta=0.52, t_{35}=1.66, p=0.107\right)$. Neither group size, the number of juveniles, age nor sex influenced isotope niche breadth (Table 2).

\section{DISCUSSION}

Despite strong claims of the ecological consequences of indirect predation effects (e.g., Preisser et al., 2005; Creel and Christianson, 2008), our observations did not suggest that impala and wildebeest living in the presence of lions foraged less or were more vigilant than impala and wildebeest living in a lion free environment. Similarly, there were no differences between the two species with respect to the influence of lions on their fGCM concentrations. We interpret these results as support for recent suggestions that the consequences of predation risk may be highly context dependent or not necessarily present at the landscape level (e.g., Périquet et al., 2010; Middleton et al., 2013). For instance, a parallel study in our study system did not find uniform effects of lion presence on zebras, but rather that that seasonal variation in food supply and vegetation dictated how lions influenced zebra's vigilance behavior and stress physiology (Périquet et al., 2017). We suggest that anti-predatory responses in many, if not most, predator-prey systems may be influenced by spatial and temporal variation in immediate predation risk, resource availability, and life history characteristics (Bolnick and Preisser, 2005; Boonstra, 2013; Courbin et al., 2016).

Despite a general lack of influence of lion presence on the behavior and stress physiology of impala and wildebeest, we found that the feces from animals in Welgevonden (where lions were present) had lower $\delta^{15} \mathrm{~N}$ values than feces from animals in Lapapala (which was lion free). Since soil ${ }^{15} \mathrm{~N}$ often is associated with higher productivity, and this is expected to be reflected in plant and also herbivore fecal nitrogen isotope values (Miranda et al., 2014), this finding may indicate that both impala and 
TABLE 2 | Estimated effects of covariates related to group (group size, number of juveniles) and individual (age, sex) characteristics on fecal glucocorticoid metabolite (fGCM) concentrations, $\delta^{13} \mathrm{C}, \delta^{15} \mathrm{~N}$, and isotope niche breadth in impala and wildebeest.

\begin{tabular}{|c|c|c|c|c|c|c|c|c|c|c|c|c|c|c|c|c|}
\hline \multirow[b]{2}{*}{ Covariate } & \multicolumn{4}{|c|}{ fGCM } & \multicolumn{4}{|c|}{$\delta^{13} \mathrm{C}(\%)$} & \multicolumn{4}{|c|}{$\delta^{15} \mathrm{~N}(\%)$} & \multicolumn{4}{|c|}{ Isotope niche breadth } \\
\hline & $\beta$ & $\boldsymbol{t}$ & df & $p$ & $\beta$ & $t$ & df & $p$ & $\beta$ & $t$ & df & $p$ & $\beta$ & $t$ & df & $p$ \\
\hline \multicolumn{17}{|l|}{ IMPALA } \\
\hline Group size & -0.01 & 0.18 & 35 & 0.860 & 0.02 & 0.03 & 53 & 0.561 & 0 & 0.15 & 53 & 0.880 & 0.01 & 0.38 & 53 & 0.704 \\
\hline Number of juveniles & 0.04 & 2.41 & 35 & 0.022 & -0.06 & 0.88 & 19 & 0.392 & -0.06 & 1.67 & 19 & 0.110 & -0.02 & 1.05 & 19 & 0.307 \\
\hline Age class ${ }^{a}$ & 0.32 & 0.89 & 35 & 0.389 & 0.25 & 0.35 & 19 & 0.728 & -0.38 & 0.14 & 19 & 0.270 & 0.12 & 0.46 & 19 & 0.625 \\
\hline Sex ${ }^{b}$ & 0.13 & 0.78 & 35 & 0.448 & 0.32 & 0.64 & 19 & 0.526 & 0.24 & 0.97 & 19 & 0.343 & -0.14 & 0.89 & 19 & 0.385 \\
\hline \multicolumn{17}{|l|}{ WILDEBEEST } \\
\hline Group size & -0.01 & 0.87 & 35 & 0.391 & -0.01 & 0.03 & 35 & 0.977 & -0.01 & 0.56 & 35 & 0.581 & 0.01 & 0.81 & 35 & 0.435 \\
\hline Number of juveniles & -0.01 & 0.06 & 35 & 0.950 & -0.01 & 1.17 & 3 & 0.327 & 0.01 & 0.24 & 3 & 0.823 & -0.01 & 0.28 & 3 & 0.792 \\
\hline Age class ${ }^{a}$ & 0.48 & 1.36 & 4 & 0.246 & -0.03 & 3.04 & 3 & 0.056 & 0.22 & 0.50 & 3 & 0.651 & -1.04 & 2.71 & 3 & 0.073 \\
\hline Sex & 0.44 & 2.30 & 4 & 0.083 & -0.01 & 0.95 & 3 & 0.412 & -0.19 & 0.76 & 3 & 0.502 & -0.11 & 0.510 & 3 & 0.64 \\
\hline
\end{tabular}

Estimated coefficients are from mixed linear models, and reflect main effects that are estimated across animals living both with and without lions.

a Nominate level was "adult."

b Nominate level was "female."

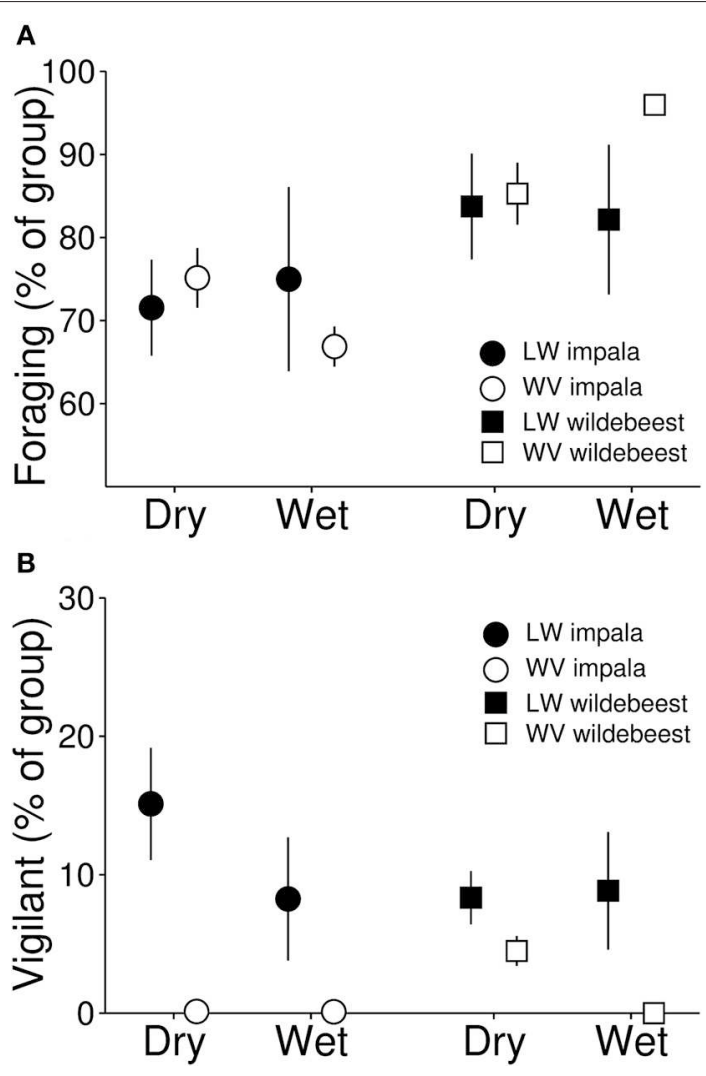

FIGURE 3 | Proportion of individuals engaged in foraging (A) and vigilance behavior (B) recorded during 335 scan observations on 33 groups of impala and 22 groups of wildebeest in Lapalala and 15 groups of impala and 11 groups of wildebeest in Welgevonden. Scan recordings were performed with 1 -min intervals for $5 \mathrm{~min}$. The figure represents means of group means $\pm 1 \mathrm{SE}$.

wildebeest may have been utilizing habitats with lower primary productivity and less grazing pressure in Welgevonden compared to Lapalala. This could reflect a habitat choice were both species

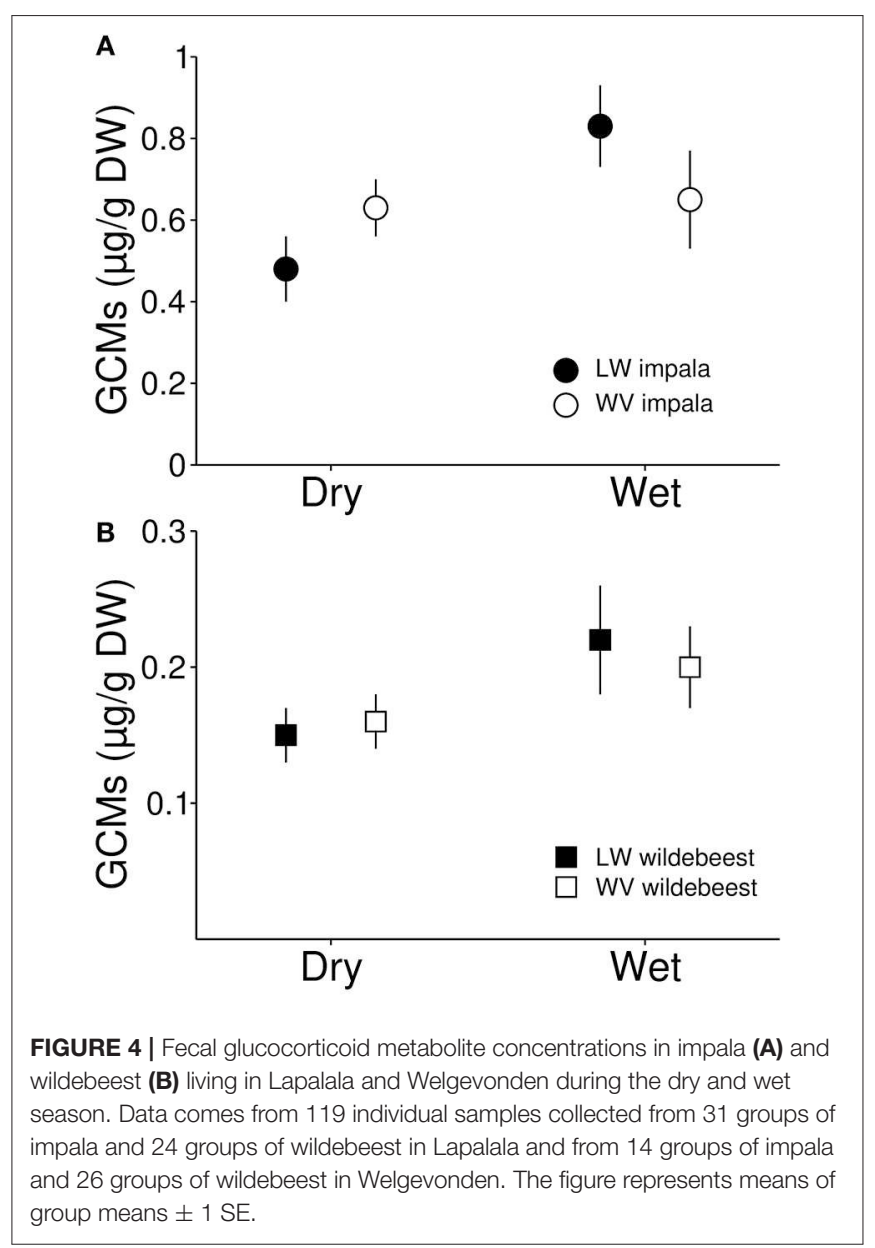

preferred areas that are less productive, but potentially safer when lions are present, although we cannot rule out that regional differences in plant $\delta^{15} \mathrm{~N}$ could partly explain the observed 


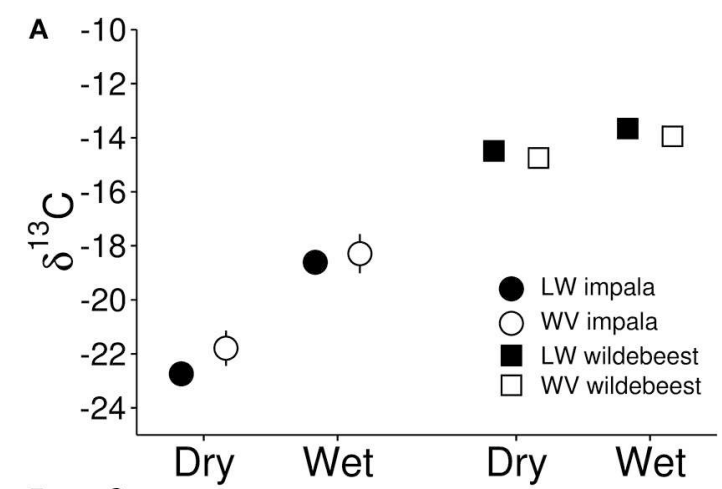

B
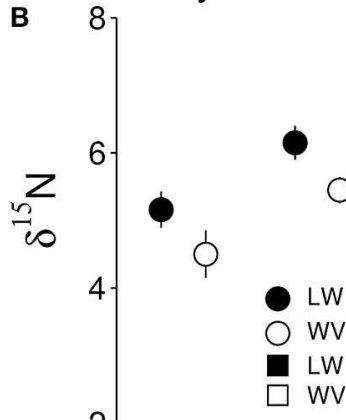

O

C

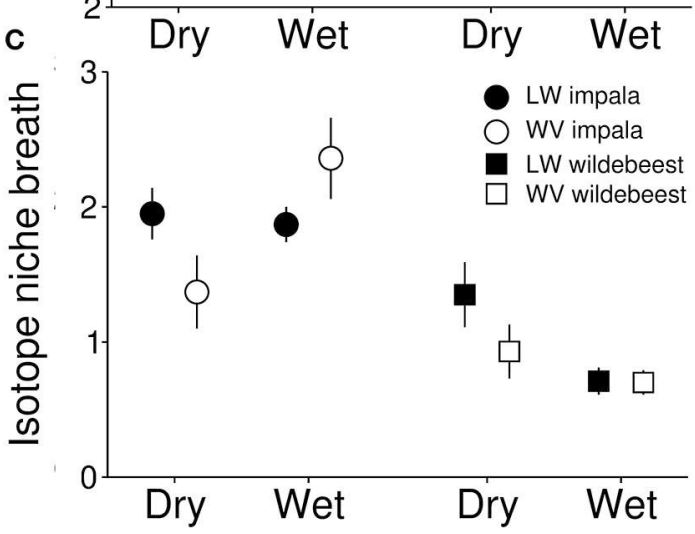

FIGURE 5 | Values of $\delta^{13} \mathrm{C}$ (A), $\delta^{15} \mathrm{~N}$ (B), and isotope niche breadth (C) from fecal samples of impala and wildebeest in the two reserves during dry and wet seasons. Isotope niche breath was quantified as the Euclidean distance of each sample to group centroids in a two-dimensional isotope space created by $\delta^{13} \mathrm{C}$ and $\delta^{15} \mathrm{~N}$ values. Figures present the mean of 46 groups of impala (containing a total of 59 individuals) and 25 groups of wildebeest (containing a total of 29 individuals) collected in Lapalala, and 17 groups of impala (containing a total of 26 individuals) and 23 groups of wildebeest (containing a total of 27 individuals) collected in Welgevonden. The figure represents means of group means \pm 1 SE.

differences as well. In both Welgevonden and Lapalala the most productive habitat tends to be associated with restricted patches in the valley bottoms, and the utilization of these areas in the presence of lions could incur elevated predation risks (e.g., Thaker et al., 2011). Such predation-induced habitat shifts have been previously observed (Caldwell, 1986; Creel et al., 2005), and recent studies have shown that ungulates may use immediate cues about predation risk when selecting where to forage (Valeix et al., 2009; Creel et al., 2014). Although the $\delta^{15} \mathrm{~N}$ data suggests that the presence of lions may have influenced the habitat use of impala and wildebeest, the $\delta^{13} \mathrm{C}$ values indicate that they did not alter their broad foraging strategies. Combined, these results points to complex and inconsistent influences of predation risk on the foraging ecology of potential prey, where some aspects of their foraging strategies may be influenced by predation risk. Such inconsistencies have ramifications for evaluating the demographic and evolutionary consequences of living under the risk of predation that warrants further attention.

Our results suggest that group characteristics (i.e., group size and composition) may have been more influential than individual characteristics (age and sex) on foraging and vigilance behavior. We argue that these results point to context dependent anti-predatory responses, where the immediate social environment combined with the intensity of predation risk and other environmental factors determine individual anti-predatory behavior. This is not a novel suggestion (Elgar, 1989; Lima and Dill, 1990), and several mechanisms have been put forward to explain how the social context may influence individual responses to predation risk (Welty, 1934; e.g., dilution and confusion effects: Hamilton, 1971; the "many eyes" hypothesis: Pulliam, 1973). However, African predators have both age and sex preferences when targeting prey (Kruuk, 1972; Schaller, 1976; FitzGibbon, 1990; Creel and Creel, 2002). The lack of strong general effects of age class and sex is therefore puzzling, but subtle adjustments of individual predation risk within the social groups, for instance by shifting to more central positions within the herds (Morrell et al., 2010) or by fine tuning anti-predatory responses to immediate risk (Lima and Bednekoff, 1999) may have been contributing factors.

We acknowledge several caveats to this study. First we appreciate the potential for a lack of spatial replication and the potential for temporal pseudoreplication. We did not have replicates of reserves with and without lions, which obviously limits the statistical sample size to one at a landscape level (Hurlbert, 1984). However, we still suggest that our results can provide useful insights into prey ecology and their proximity to an apex predator, although we acknowledge that more data are needed before our interpretations can be applied to different geographic areas and ecological systems. In addition, we appreciate that the lions had only been present for 10-14 ears in Welgevonden at the time of our study. Although observations from the northern hemisphere suggest a low retention of anti-predatory behavior (Berger, 2007), such lack of retention appears not to be uniform (Hettena et al., 2014). This agrees with evolutionary arguments for the retention of anti-predatory behaviors in multi-predator environments (Blumstein, 2006), such as the one in South Africa (Dalerum et al., 2008b). We therefore regard it as likely that the animals in Welgevonden were exhibiting the same range of anti-predatory behavior to that of populations that had not experienced an ecological period without lions. We also did not work with marked groups and individuals, so that we cannot rule out that we sampled the same individuals in different years or seasons. However, we sampled a very small portion of the total populations, and we therefore regard such repeated sampling relatively unlikely. We did not distinguish routine vs. intense vigilance. Animals usually keep eating during routine vigilance, while intense vigilance constrains food intake as chewing is arrested (Périquet et al., 2012). We 
can therefore not rule out qualitative alterations in foraging and vigilance behavior. Finally, although Lapalala was a lion-free environment, the presence of other predators, such as wild dog, brown hyena and leopard (Dalerum and Belton, 2015) may have balanced the anti-predator responses of prey in several ways due to their diverse hunting techniques (Schmitz, 2008).

Despite these caveats, we highlight that our data set comprised data collected over several years, and we found consistent results across several different data types. We therefore argue that our study provided clear observations that the additions of lions to a reserve did not have any substantial effects on the behavior, physiology and foraging ecology of these two common African ungulates. However, stable isotope data suggested a potential habitat shift in the presence of lions, with could have involved animals utilizing areas of lower productivity. Our results provide support for context dependent, complex and potentially conflicting responses of anti-predatory responses to apex predator presence. We suggest that further research is needed to identify at what scales anti-predator responses occur, at what spatial and temporal scales they have ecological and demographic effects, and how spatial and temporal variation in environmental conditions interact with prey life history in shaping indirect predation effects.

\section{DATA AVAILABILITY STATEMENT}

The dataset for this study is available in figshare (https://figshare. com, doi: 10.6084/m9.figshare.7334261).

\section{AUTHOR CONTRIBUTIONS}

MC contributed to field data collection, laboratory analyses, data analyses, and wrote the initial drafts of the manuscript. LB

\section{REFERENCES}

Abramsky, Z., Rosenzweig, M. L., and Subach, A. (2002). The costs of apprehensive foraging. Ecology 83:1330. doi: 10.1890/0012-9658(2002)083[1330:TCOAF]2.0. $\mathrm{CO} ; 2$

Altmann, J. (1974). Observational study of behavior: sampling methods. Behavior 49, 227-267. doi: 10.1163/156853974X00534

Ambrose, S. H. (1991). Effects of diet, climate and physiology on nitrogen isotope abundances in terrestrial food webs. J. Archaeol. Sci. 18, 293-317. doi: 10.1016/0305-4403(91)90067-Y

Ambrose, S. H., and De Niro, M. J. (1986). The isotopic ecology of East African mammals. Oecologia 69, 395-406. doi: 10.1007/BF00377062

Bateman, P. H., Fleming, P. A. (2017). Are negative effects of tourist activities on wildlife over-reported? A review of assessment methods and empirical results. Cons. Biol. 211, 10-19. doi: 10.1016/j.biocon.2017. 05.003

Ben-Shahar, R. (1987). Grasses and habitat relationships on a sour bushveld nature reserve. Vegetation 72, 45-49. doi: 10.1007/BF00044951

Berger, J. (2007). Carnivore repatriation and Holarctic prey: narrowing the deficit in ecological effectiveness. Conserv. Biol. 21, 1105-1116. doi: 10.1111/j.1523-1739.2007.00729.x

Blumstein, D. T. (2006). The multipredator hypothesis and the evolutionary persistence of antipredatory behavior. Ethology 112, 209-217. doi: 10.1111/j.1439-0310.2006.01209.x contributed to field data collection and analyses of behavioral data. AG was responsible for analyses of endocrine samples. IG contributed to field data collection and laboratory analyses. $\mathrm{GH}$ was responsible for analyses of stable isotope samples. LS contributed to field data collection. FD conceptualized the study, coordinated and conducted field data collection, coordinated laboratory analyses, designed and conducted data analyses, and wrote parts of the manuscript. All authors contributed to complete the final draft of the manuscript.

\section{FUNDING}

Funding was provided by the National Geographic/Wait's Foundation (grant number W32-08), the National Research Foundation in South Africa (grant numbers SFP2008072900003 and IFR2011032400087), and the Ministry of Economy and Competitiveness in Spain (grant number RYC-201314662).

\section{ACKNOWLEDGMENTS}

We are grateful to managers and staff at Lapalala Wilderness and Welgevonden Game Reserve for permission to carry out the research and for logistic support. Adrian Tordiffe of the National Zoological Gardens in Pretoria kindly assisted with the ACTH validation experiment, and Maria Miranda and Pete Richardson assisted with behavioral recordings.

\section{SUPPLEMENTARY MATERIAL}

The Supplementary Material for this article can be found online at: https://www.frontiersin.org/articles/10.3389/fevo. 2018.00191/full\#supplementary-material

Bolnick, D. I., and Preisser, E. L. (2005). Resource competition modifies the strength of trait mediated predator-prey interactions: a meta-analysis. Ecology 86, 2771-2779. doi: 10.1890/04-1249

Boonstra, R. (2013). Reality as the leading cause of stress: rethinking the impact of chronic stress in nature. Funct. Ecol. 27, 11-23. doi: 10.1111/1365-2435.12008

Boonstra, R., Hik, D., Singleton, G. R., and Tlnnikov, A. (1998). The impact of predator-induced stress on the snowshoe hare cycle. Ecol. Monogr. 68, 371-394. doi: 10.1890/0012-9615(1998)068[0371:TIOPIS]2.0.CO;2

Caldwell, G. (1986). Predation as a selective force on foraging herons: effects of plumage color and flocking. Auk 103, 494-505.

Clinchy, M., Zanette, L., Boonstra, R., Wingfield, J. C., and Smith, J. N. (2004). Balancing food and predator pressure induce chronic stress in songbirds. Proc. R. Soc. Lond. Ser. B. 271, 2473-2479. doi: 10.1098/rspb.2004.2913

Clutton-Brock, T. H., O’Riain, M. J., Brotherton, P. N., Gaynor, D., Kansky, R., Griffin, A. S., et al. (1999). Selfish sentinels in cooperative mammals. Science 284, 1640-1644. doi: 10.1126/science.284.5420.1640

Codron, D., Codron, J., Lee-Thorp, J., Sponheimer, M., and De Ruiter, D. (2005). Animal diets in the Waterberg based on stable isotopic composition of faeces. S. Afr. J. Wildl. Res. 35, 43-52.

Codron, D., Codron, J., Lee-Thorp, J. A., Sponheimer, M., de Ruiter, D., Sealy, J., et al. (2007). Diets of savanna ungulates from stable carbon isotope composition of faeces. J. Zool. 273, 21-29. doi: 10.1111/j.1469-7998.2007.00292.x

Codron, J., Codron, D., Lee-Thorp, J. A., Sponheimer, M., Bond, W. J., de Ruiter, D., et al. (2005). Taxonomic, anatomical, and spatio-temporal variations in the 
stable carbon and nitrogen isotopic compositions of plants from an African savanna. J. Archeol. Sci. 32, 1757-1772. doi: 10.1016/j.jas.2005.06.006

Courbin, N., Loveridge, A. J., Macdonald, D. W., Fritz, H., Valeix, M., Makuwe, E. T., et al. (2016). Reactive responses of zebras to lion encounters shape their predator-prey space game at large scale. Oikos 125, 829-838. doi: 10.1111/oik.02555

Creel, S., and Christianson, D. (2008). Relationships between direct predation and risk effects. Tr. Ecol. Evol. 23, 194-201. doi: 10.1016/j.tree.2007.12.004

Creel, S., and Christianson, D. (2009). Wolf presence and increased willow consumption by Yellowstone elk: Implications for trophic cascades. Ecology 90 , 2454-2466. doi: 10.1890/08-2017.1

Creel, S., and Creel, N. M. (2002). The African Wild Dog: Behavior, Ecology, and Conservation. Princeton: Princeton University Press.

Creel, S., Schuette, P., and Christianson, D. (2014). Effects of predation risk on group size, vigilance, and foraging behavior in an African ungulate community. Behav. Ecol. 25, 773-784. doi: 10.1093/beheco/aru050

Creel, S., Winnie, J. A., and Christianson, D. (2009). Glucocorticoid stress hormones and the effect of predation risk on elk reproduction. Proc. Natl. Acad. Sci. U.S.A. 106, 12388-12393. doi: 10.1073/pnas.0902235106

Creel, S., Winnie, J. Jr., Maxwell, B., Hamlin, K., and Creel, M. (2005). Elk alter habitat selection as an antipredator response to wolves. Ecology 86, 3387-3397. doi: 10.1890/05-0032

Dalerum, F., and Belton, L. (2015). African ungulates recognize a locally extinct native predator. Behav. Ecol. 26, 215-222. doi: 10.1093/beheco/aru180

Dalerum, F., Cameron, E. Z., Kunkel, K., and Somers, M. J. (2009). Diversity and depletions in continental carnivore guilds: implications for prioritizing global carnivore conservation. Biol. Lett. 5, 35-38. doi: 10.1098/rsbl.2008.0520

Dalerum, F., Lange, H., Skarpe, C., Rooke, T., Inga, B. H., and Bateman, P. W. (2008a). Group size, antipredatory vigilance and foraging competition in two species of gregarious antelope. S. Afr. J. Wildl. Res. 38, 138-145. doi: 10.3957/0379-4369-38.2.138

Dalerum, F., Perbro, A., Magnusdottir, R., Hersteinsson, P., and Angerbjörn, A. (2012). The influence of coastal access on isotope variation in Icelandic Arctic foxes. PLoS ONE 7:e32071. doi: 10.1371/journal.pone.0032071

Dalerum, F., Somers, M. J., Kunkel, K. E., and Cameron, E. Z. (2008b). The potential for large carnivores to act as biodiversity surrogates in southern Africa. Biodiv. Cons. 17, 2939-2949. doi: 10.1007/s10531-008-9406-4

de Haast, R. A. (2016). Monitoring Adrenocortical Function as a Measure of Stress in Blue Wildebeest (Connochaetes taurinus). Pretoria: University of Pretoria, MSc thesis.

Dias, P. A. D., Rangel-Negrín, A., and Canales-Espinosa, D. (2011). Effects of lactation on the time-budgets and foraging patterns of female black howlers (Alouatta pigra). Am. J. Phys. Anthrop. 145, 137-146. doi: 10.1002/ajpa. 21481

Dobson, A. (2009). Food-web structure and ecosystem services: insights from the Serengeti. Philos. Trans. R. Soc. B. 364, 1665-1682. doi: 10.1098/rstb.2008.0287

Dobson, H., and Smith, R. F. (2000). What is stress, and how does it affect reproduction. Anim. Repr. Sci. 60-61, 743-752. doi: 10.1016/S0378-4320(00)00080-4

du Toit, J., Rogers, K., Biggs, H. (2004). The Kruger Experience: Ecology and Management of Savanna Heterogeneity. New York, NY: Island Press.

Elgar, M. A. (1989). Predator vigilance and group size in mammals and birds: a critical review of the empirical evidence. Biol. Rev. 64, 13-33. doi: 10.1111/j.1469-185X.1989.tb00636.x

Farquhar, G. D., Ehleringer, J. R., and Hubik, K. T. (1989). Carbon isotope discrimination and photosynthesis. Ann. Rev. Plant Physiol. 40, 503-537. doi: 10.1146/annurev.pp.40.060189.002443

FitzGibbon, C. D. (1990). Why do hunting cheetahs prefer male gazelles? Anim. Behav. 40, 837-845. doi: 10.1016/S0003-3472(05)80984-4

Ganswindt, A., Tordiffe, A. S., Stam, E., Howitt, M., and Jori, F. (2012). Determining adrenocortical activity as a measure of stress in African buffalo (Syncerus caffer) based on fecal analysis. Afr. Zool. 47, 261-269. doi: 10.1080/15627020.2012.11407558

Hamilton, W. D. (1971). Geometry for the selfish herd. J. Theor. Biol. 31, 295-311. doi: 10.1016/0022-5193(71)90189-5

Handley, L. L., and Raven, J. A. (1992). The use of natural abundance of nitrogen isotopes in plant physiology and ecology. Plant Cell Environ. 15, 965-985. doi: 10.1111/j.1365-3040.1992.tb01650.x
Hawlena, D., and Schmitz, O. J. (2010). Physiological stress as a fundamental mechanism linking predation to ecosystem functioning. Am. Nat. 176, 537-556. doi: $10.1086 / 656495$

Hayward, M., and Kerley, G. (2005). Prey preferences of the lion (Panthera leo). J. Zool. 267, 309-322. doi: 10.1017/S0952836905007508

Heistermann, M., Tari, S., and Hodges, J. K. (1993). Measurement of fecal steroids for monitoring ovarian function in New World primates, Callitrichidae. J. Reprod. Fertil. 99, 243-251. doi: 10.1530/jrf.0.0990243

Hettena, A. M., Munoz, N., and Blumstein, D. T. (2014). Prey responses to predator's sounds: a review and empirical study. Ethology 120, 427-452. doi: $10.1111 /$ eth.12219

Hofmann, R. R., and Stewart, D. R. M. (1972). Grazer or browser: a classification based on the stomach structure and feeding habits of East African ruminants. Mammalia 36, 226-240. doi: 10.1515/mamm.1972.36.2.226

Hulsman, A., Dalerum, F., Ganswindt, A., Muencher, S., Bertshinger, H., and Paris, M. (2011). Non-invasive monitoring of glucocorticoid metabolites in brown hyaena (Hyaena brunnea) faeces. Zoo Biol. 30, 451-458. doi: 10.1002/zoo.20325

Hurlbert, S. H. (1984). Pseudoreplication and the design of ecological field experiments. Ecol. Monogr. 54, 187-211. doi: 10.2307/1942661

Isaacs, L., Somers, M. J., and Dalerum, F. (2013). Effects of prescribed burning and mechanical bush clearing on ungulate space use in an African savannah. Restor. Ecol. 21, 260-266. doi: 10.1111/j.1526-100X.2012.00877.x

Jarman, P. J. (1974). The social organization of antelope in relation to their ecology. Behavior 48, 215-267. doi: 10.1163/156853974X00345

Kilian, P. J. (2003). The Ecology of Reintroduced Lions on the Welgevonden Private Game Reserve, Waterberg. Pretoria: University of Pretoria, MSc Thesis.

Kruuk, H. (1972). The Spotted Hyena: A Study of Predation and Social Behavior. Chicago, IL: The University of Chicago Press.

Lima, S. L. (1995). Back to the basics of anti-predatory vigilance: the group size effect. Anim. Behav. 49, 11-20. doi: 10.1016/0003-3472(95)80149-9

Lima, S. L. (1998). Nonlethal effects in the ecology of predator-prey interactions. Bioscience 48, 25-34. doi: 10.2307/1313225

Lima, S. L., and Bednekoff, P. A. (1999). Temporal variation in danger drives antipredator behavior: the predation risk allocation hypothesis. Am. Nat. 153, 649-659. doi: $10.1086 / 303202$

Lima, S. L., and Dill, L. M. (1990). Behavioral decisions made under the risk of predation: a review and prospectus. Can. J. Zool. 68, 629-640. doi: 10.1139/z90-092

Low, A. B., and Rebelo, T. G. (1996). Vegetation of South Africa, Lesotho and Swaziland. Pretoria: Department of Environmental Affairs and Tourism.

Middleton, A. D., Kauffman, M. J., McWhirther, E. J., Jimenez, M. J., Cook, R. C., Cook, J. G., et al. (2013). Linking anti-predator behavior to prey demography reveals limited risk effects of an actively hunting large carnivore. Ecol. Lett. 16, 1023-1030. doi: 10.1111/ele.12133

Miranda, M., Dalerum, F., and Parrini, F. (2014). Interaction patterns within a multi-herbivore assemblage derived from stable isotopes. Ecol. Complex. 20, 51-60. doi: 10.1016/j.ecocom.2014.08.002

Morrell, L. J., Ruxton, G. D., and James, R. (2010). Spatial positioning in the selfish herd. Behav. Ecol. 22, 16-22. doi: 10.1093/beheco/arq157

Möstl, E., and Palme, R. (2002). Hormones as indicators of stress. Domest. Anim. Endocrinol. 23, 67-74. doi: 10.1016/S0739-7240(02)00146-7

Mucina, L., and Rutherford, M. C. (2006). The Vegetation of South Africa, Lesotho and Swaziland. Sterlitzia 19. Pretoria: SANBI.

Owen-Smith, N. (2008). Changing vulnerability to predation related to season and sex in an African ungulate assemblage. Oikos 117, 602-610. doi: 10.1111/j.0030-1299.2008.16309.x

Palme, R., and Möstl, E. (1997). Measurement of cortisol metabolites in faeces of sheep as a parameter of cortisol concentration in blood. Int. J. Mammal Biol. 62, 192-197.

Périquet, S., Richardson, P., Cameron, E. Z., Ganswindt, A., Belton, L., Loubser, E., et al. (2017). Effects of lions on behavior and endocrine stress in plains zebras. Ethology 123, 667-674. doi: 10.1111/eth.12638

Périquet, S., Todd-Jones, L., Valeix, M., Stapelkamp, B., Elliot, N., Wijers, M., et al. (2012). Influence of immediate predation risk by lions on the vigilance of prey of different body size. Behav. Ecol. 23, 970-976. doi: 10.1093/beheco/ ars060

Périquet, S., Valeix, M., Loveridge, A. J., Madzikanda, H., Macdonald, D. W., and Fritz, H. (2010). Individual vigilance of African herbivores while drinking: 
the role of immediate predation risk and context. Anim. Behav. 79, 655-671. doi: 10.1016/j.anbehav.2009.12.016

Pinheiro, J., Bates, D., DebRoy, S., Sarkar, D., and R Core Team (2018). nlme: Linear and Nonlinear Mixed Effects Models. R package version 3.1-131.1. Available online at: https://CRAN.R-project.org/package $=$ nlme

Pool-Stanvliet, R. (2013). A history of the UNESCO Man and the biosphere programme in South Africa. S. Afr. J. Sci. 109, 1-6. doi: 10.1590/sajs.2013/a0035

Preisser, E. L., Bolnick, D. I., and Benard, M. F. (2005). Scared to death? The effects of intimidation and consumption in predator-prey interactions. Ecology 86, 501-509. doi: 10.1890/04-0719

Pulliam, H. R. (1973). On the advantages of flocking. J. Theor. Biol. 38, 419-422. doi: 10.1016/0022-5193(73)90184-7

Ramnanan, R., Swanepoel, L., and Somers, M. (2013) The diet and presence of African wild dogs (Lycaon pictus) on private land in the Waterberg region, South Africa. S. Afr. J. Wildl. Res. 43, 68-73. doi: 10.3957/056.043.0113

Roberts, G. (1996). Why individual vigilance declines as group size increases. Anim. Behav. 51, 1077-1086. doi: 10.1006/anbe.1996.0109

Sagamiko, T. D., Shaban, N., Nahonyo, C. L., Makinde, O. D. (2015). Optimal control of a threatened wildebeest-lion prey-predator system incorporating a constant prey refuge in the Serengeti ecosystem. Appl. Comput. Mathem. 4, 296-312. doi: 10.11648/j.acm.20150404.18

Sand, H., Wikenros, C., Wabakken, P., Liberg, O. (2006). Cross-continental differences in patterns of predation: will naive moose in Scandinavia ever learn? Proc. R. Soc. Lond. Ser. B. 273, 1421-1427. doi: 10.1098/rspb.2005.3447

Sapolsky, R. M., Romero, L. M., and Munck, A. U. (2000). How do glucocorticoids influence stress responses? Integrating permissive, suppressive, stimulatory, and preparative actions. Endocr. Rev. 21, 55-89. doi: 10.1210/er.21.1.55

Schaller, G. B. (1976). The Serengeti Lion: A Study of Predator-Prey Relations. Chicago, IL: The University of Chicago Press.

Schmitz, O. J. (2008). Effects of predator hunting mode on grassland ecosystem function. Science 319, 952-964. doi: 10.1126/science. 1152355

Sih, A., and McCarthy, T. M. (2002). Prey responses to pulses of risk and safety: testing the risk allocation hypothesis. Anim. Behav. 63, 437-443. doi: 10.1006/anbe.2001.1921

Sinclair, A. R. E., Mduma, S., and Brashares, J. S. (2003). Patterns of predation in a diverse predator-prey community. Nature 425, 288-290. doi: 10.1038 /nature01934

Skead, C. J. (2011). Historical Incidence of the Larger Land Mammals in the Broader Western and Northern Cape. 2nd Edn. Port Elizabeth: Centre for African Conservation Ecology, Nelson Madela Metropolitan University.
Swanepoel, L. H. (2008). Ecology and Conservation of Leopards, Panthera pardus, on Selected Game Ranches in the Waterberg Region, Limpopo, South Africa. Pretoria: University of Pretoria, MSc Thesis.

Swanepoel, L. H., Somers, M. J., and Dalerum, F. (2015). Density of leopards Panthera pardus on protected and non-protected land in the Waterberg Biosphere, South Africa. Wildl. Biol. 21, 263-268. doi: 10.2981/wlb.00108

Thaker, M., Vanak, A., Owen, C., Ogden, M., Niemann, S., and Slotow, R. (2011). Minimizing predation risk in a landscape of multiple predators: effects on the spatial distribution of African ungulates. Ecology 92, 398-407. doi: 10.1890/10-0126.1

Touma, C., and Palme, R. (2005). Measuring fecal glucocorticoid metabolites in mammals and birds: the importance of validation. Ann. N. Y. Acad. Sci. 1046, 54-74. doi: 10.1196/annals.1343.006

Valeix, M., Loveridge, A. J., Chamaillé-Jammes, S., Davidson, Z., Murindagomo, F., Fritz, H., et al. (2009). Behavioral adjustments of African herbivores to predation risk by lions: Spatiotemporal variations influence habitat use. Ecology 90, 23-30. doi: 10.1890/08-0606.1

Venables, W. N., and Ripley, B. D. (2002). Modern Applied Statistics with S. 4th Edn. New York, NY: Springer.

Wellington, J. H. (1955). Southern Africa: A Geographical Study, Vol. 1. Cambridge: University Press.

Welty, J. C. (1934). Experiments in group behavior of fishes. Physiol. Zool. 7, 85-128. doi: 10.1086/physzool.7.1.30151215

Werner, E. E., Gilliam, J. F., Hall, D. J., and Mittelbach, G. G. (1983). An experimental test of the effects of predation risk on habitat use in fish. Ecology 64, 1540-1548. doi: 10.2307/1937508

Wolff, J. O., and Van Horn, T. (2003). Vigilance and foraging patterns of American elk during the rut in habitats with and without predators. Can. J. Zool. 81, 266. doi: $10.1139 /$ z03-011

Conflict of Interest Statement: The authors declare that the research was conducted in the absence of any commercial or financial relationships that could be construed as a potential conflict of interest.

Copyright (c) 2018 Chizzola, Belton, Ganswindt, Greco, Hall, Swanepoel and Dalerum. This is an open-access article distributed under the terms of the Creative Commons Attribution License (CC BY). The use, distribution or reproduction in other forums is permitted, provided the original author(s) and the copyright owner(s) are credited and that the original publication in this journal is cited, in accordance with accepted academic practice. No use, distribution or reproduction is permitted which does not comply with these terms. 